\title{
The Use of Drone in Risk Assessing of the Mining Works Performance - Case Study
}

\author{
Branimir Farkaš $\check{1}^{1}$ Ana Hrastov ${ }^{2}$, Ivo Galić ${ }^{1}$ \\ ${ }^{1}$ Mining, geology and petroleum engineering faculty, 10000, Zagreb, Croatia \\ ${ }^{2}$ NikoleTesle 21, 47280, Ozalj, Croatia
}

doi: https://doi.org/10.21467/abstracts.93.6

\begin{abstract}
A BST RA CT
Monitoring of the mining works performance and their success as well as the assessment of possible risks is one of the daily requirements in mining. One of the most important segments of mineral exploitation is the condition of the mine works after blasting since people's safety can be compromised after blasting. Very often, due to the terrain morphology and limited or even disabled access to the benches, it is not possible to capture all points and collect data using classical surveying methods. In order to reduce the risk of any threat, it is necessary to monitor the mining works and evaluate the success of their performance in a safe manner, and this is possible using unmanned aerial vehicles e.g. drones.

In this article data collection and risk analysis was done on the surface quarry "Tambura", located in the Republic of Croatia, in the western part of the Istrian peninsula, about $8 \mathrm{~km}$ northwest of Pula. The quarry "Tambura" in which a crushed building stone is mined is covering a total area of 3,79 ha and is wide $285 \mathrm{~m}$ and long $181 \mathrm{~m}$. As a result of blasting in the south part of the quarry, too much rock was blasted in the form of rock material overcut on the highest bench. This compromised the stability of the bench, surrounding terrain and therefore the safety of people inside and outside of the quarry. The analysis of the mining works performance and risk assessment was carried out in five steps:

1) Identifying potential hazards and risks (identifying hazards that could cause harm and anticipate occupational hazards and circumstances that may cause potential hazards that cause harm, injury or illness), 2) Identifying participants at risk and how they are exposed to risk (identifying workers and other people who may be exposed to hazards and determining how and in what way, how long and how often workers are exposed to hazards/risks),

3) Risk assessment (assess the likelihood of an adverse event occurring and the severity of the possible consequence and to conclude on the gravity of the possible consequences),

4) Documenting and recording the results of the risk assessment (documenting the identified hazards, hazardous situations and exposure characteristics and recording the results of the risk assessment),

5) Decision on corrective and preventive measures (identifying appropriate activities and actions to minimize or reduce risk and prioritize the implementation of preventive and corrective measures).

Site data (aerial digital photographs) were collected with the photogrammetric data collection method instead of conventional surveying methods using unmanned aerial vehicle DLI Phantom 4 Pro V2.0 (drone weight 1375 g, camera sensor 1" CMOS, effective pixels 20M, remote controller max transmission distance FCC: $7 \mathrm{~km}, \mathrm{CE}: 4 \mathrm{~km}$ ). 12 control points were marked on the ground surface and measured with high accuracy of $\pm 3 \mathrm{~cm}$ error in both horizontal and vertical direction. The photographs were taken at the height of $50 \mathrm{~m}$ above the ground surface and were acquired in two flyovers. Aerial photos overlap was $80 \%$ and the ground sampling distance (GSD) was 1,45 cm/px and a total of 785 photographs were taken and processed in Bentley Context Capture CONNECT Edition software.
\end{abstract}

C) 2020 Copyright held by the author(s). Published by AIJR Publisher in "Abstracts of The Second Eurasian RISK-2020 Conference and Symposium" April 12- 19, 2020, Tbilisi, Georgia. Jointly organized by AMIR Technical Services LLC, Georgian Technica University, Institute of Geography (Kazakhstan) and Russian Institute of Petroleum Geology and Geophysics.

DOI: $10.21467 /$ abstracts.93 
The Second Eurasian RISK-2020 Conference and Symposium

Analysis of the risk assessment was made using two different models: a three-dimensional photogrammetric model and two-dimensional orthophoto model of the terrain and mining works. The risk analysis was performed after blasting on $30 \times 150 \mathrm{~m}$ area located in the south part of the quarry. The analysed area is a part of the highest bench with a maximum height of $23 \mathrm{~m}$ in the eastern part, which decreases to only $5 \mathrm{~m}$ on the western part with designed bench slope of $70^{\circ}$. First analysis was carried out on the two-dimensional orthophoto model created from the collected aerial data. The area was analysed by plotting the peak parts of the bench after blasting and comparing them with the designed mining works contours. The analysis revealed that the mining works after blasting correlates to the design parameters and that they were performed with great precision. Measurement was conducted at regular intervals of 10 meters, and a total of 19 measurements were made. The average deviation of the performed mining works in relation to the mine design is 0,816 meters while the minimum deviation is $0,042 \mathrm{~m}$ and the maximum deviation is 3,497 $\mathrm{m}$. Second analysis was carried out on the three-dimensional photogrammetric model. The 19 measurements were carried out at the same locations as well as on the two-dimensional orthophoto model in order to compare the results. Considering the three-dimensional model display capabilities, parts of the highest bench were observed, where a part of the rock mass was over blasted behind the designed slope and below the terrain. A mining works line was plotted on the parts of the bench toe where the maximum deviation from planned mining operation were assumed. The minimum deviation of the performed mining works from the planned state is $0,096 \mathrm{~m}$, the maximum deviation is $4,686 \mathrm{~m}$ and the average deviation is $1,025 \mathrm{~m}$.

The continuous insight into the mining works performance in relation to the mine planned model is a necessity of every mining operation. The application of this method allows for fast and easy but above all secure data collection from a safe distance. Based on the performed analyses, a greater deviation of the performed mining works on the three-dimensional photogrammetric model is observed compared to the two-dimensional model. The reason for this is the ability to display terrain and bench parts with a threedimensional model that are not available or difficult to display in a two-dimensional model. The risk assessment based on the two-dimensional model does not provide sufficiently precise results for deciding on corrective and preventive measures for risk prevention. On the other side development of the threedimensional model of the current situation ensures the assessment of possible risks in the shortest possible time and its timely prevention so the best risks correctional and prevention measures can be brought. 